\title{
Development and Validation of a Questionnaire to Measure Perceptions of Freedom of Choice in Digital Games
}

\author{
Sotiris Kirginas, Dimitris Gouscos \\ University of Athens \\ \{skirginas, gouscos\}@media.uoa.gr
}

\begin{abstract}
The purposes of this study were (a) to develop a valid and reliable questionnaire using both the structural characteristics of digital games and students perceptions of the concept of freedom of choice in digital games, (b) to validate items to be used in questionnaire to measure perceived freedom of choice, (c) to identify the factors that underlie freedom of choice in digital games and (d) to generate a model to predict preferred freedom of choice in digital games from gender, age, familiarity with digital game and frequency of digital game use. The study consisted of four phases. First, 9 items were developed though a comprehensive literature review and a focus groups method. Second, the items were refined through three layers of review. Third, 290 primary school students rated the results of the reviews. Fourth, exploratory factor analysis (EFA) were employed to analyze the data. The results of the Freedom of Choice (FoC) Questionnaire were statistically significant with a total of 9 items across two factors (exploratory freedom - outcome freedom). Furthermore, a model was constructed, based on a multiple regression, in order to predict preferred freedom of choice in digital games from different demographic characteristics of players. This work can be implemented in serious games; if serious games include the characteristics of free-form play can lead to more engaging and more free-form learning processes, which can better support innovative approaches to learning and, more generally, to the acquisition of 21st century transferable skills. This effort is contextualized within a broader research plan for using digital games (adventure games, in particular) as learning frameworks, with a view to ultimately taking stock of positive player experience drivers, such as freedom of choice, as enablers for better player/learner engagement and more effective learning.
\end{abstract}

Keywords: Digital Games, Freedom of Choice, Player Perceptions, Free-form Gameplay, Formally Structured Gameplay, Questionnaire, Measurement, Validation, Adventure Games, Games for Learning;

\section{Introduction}

The single most important factor that makes a digital game successful is the quality of players' experience. A digital game should be fun, challenging and exciting in order to provide the best gaming experience and produce positive emotions within the player. This need is even greater especially when we talk about digital games for learning purposes.

Player experience is a multidimensional concept which describes various qualities of interactivity in games and has been related to other concepts such as flow [1,2,3], presence [4,5], immersion [69], pleasure [10], motivation [11-13], enjoyment [14,15] and fun [15-17].

There are 3 phases of player experience [18, 19]: (a) expected player experience (before a player starts to interact with a game), (b) player experience during interaction (experience that takes place while interacting with the game), and (c) overall player experience (experience after game ends). From the above three phases of player experience the most crucial one is player experience during interaction. Investigating the player experience during interaction is important in order to improve 
a game, as it is in this phase that features and components which create positive experience and others which do not can be observed. To understand player experience during the interaction phase, we need to see the effect of three aspects to player experience:

- User's internal state (predispositions, expectations, needs, motivation, mood, etc.), the characteristics of the designed system (e.g. complexity, purpose, usability, functionality, etc.)

- $\quad$ The system (e.g. complexity, purpose, usability, functionality, etc)

- The context (or the environment) within which the interaction occurs (e.g. organisational/social setting, meaningfulness of the activity, voluntariness of use, etc.).

In this research we are leaving aside, on purpose, the human (user) aspect (first aspect) as well as the social dimensions of playing digital games (third aspect) and we are focusing on the second aspect, the system (game).

A digital game as a system has two sets of features which affect player experience and enhance interactivity. The first set of features is the mechanics of the game. The mechanics are methods invoked by players for interacting with the game world, including goals, rules and rewards [20, 21]. Goals are what a player must do and accomplish in order to progress or win in the game. Rules are the laws that determine what can and cannot happen in the game [22]. Rewards are something a player receives in return for completing goals or specific objectives, tasks and challenges. The second set of features is the interface including visuals, audio and feedback. Visuals are related to how the game looks, in two or three dimensions. Audio is the game's sounds, sound effects and music, equally important when compared to visuals in creating atmosphere and for player feedback. Feedback is the game's response (visual or audio) to players' actions [23].

In the light of this, and considering the view of Mark Wolf [24] that the smallest unit of interactivity in a game is the choice, we focus our research on the relationship between the player's choice and the game's response which characterize the depth and quality of interaction.

In this respect, and using the notion of player's choice as core concept, this paper aims at the qualitative assessment of a concept of freedom of play in order to (a) develop a valid and reliable questionnaire using both the structural characteristics of digital games and students perceptions of the concept of freedom of choice in digital games, (b) validate items to be used in such a questionnaire to measure perceived freedom of choice, (c) identify the factors that underlie freedom of choice in digital games and (d) generate a model to predict preferred freedom of choice in digital games from gender, age, familiarity with digital game and frequency of digital game use.

\section{The concept of freedom of choice}

The idea that freedom of choice is primary factor for leading a good life is not a new one. Given this it is easy to understand the significance of freedom of choice to evaluate the kind of gameplay. In the literature review there are two different ways of viewing freedom each of which has been explored by scholars over a long time [25]. According to the first approach, there is a "positive" view of freedom, focus on what a person can choose to do or achieve, rather than on the absence of any particular type of restraint that prevents him or her from doing one thing or another; according to the second approach, there is a "negative" view of freedom focuses precisely on the absence of a class of restraints that one person may exercise over another, or indeed the state may exercise over individuals. It is clear that both approaches have much to offer for assessing the freedom of gameplay.

In digital games freedom of choice can be achieved within three different areas in relation to games. First, players may have choices to do with rules as a part of the gameplay. Second, they may have choices on which actions to perform as part of the gameplay to affect the outcome of the game. Third, they may have choices to be engaged in other types of activities while the gameplay progresses [26]. An important aspect of designing for freedom of choice in gameplay is to be aware that the allowing players several different ways of affect game states is not the most critical issue; it is that they perceive they have it. Furthermore, as argued by Sid Meier " $a$ good game is a series of interesting choices". In an interesting choice, no single option is clearly better than the other options, the options are not equally attractive, and the player must be able to make an informed choice [27].

Choices without consequences are meaningless. Whenever a player makes a choice this can be a "good" or a "bad" choice depending on the consequences that follow it. There are "good" choices, (e.g. gaining abilities or powers, increasing score etc.), which reward players' knowledge or good strategy and help them to improve their gaming experience, as well as "bad" choices, (e.g. losing lives, losing a turn in gameplay, not increasing score etc.) which penalize lack of knowledge or bad 
strategy. Still, in a game world, even making "bad" choices is meaningful, as this allows players to try and make mistakes or fail, and then try again without any negative real-world consequences.

That said, though, the real-world counterpart of "good" and "bad" choices within a (serious) game, is an independent issue. Game designers may decide to present as good choices (in the in-game sense of the term) decisions which would not be acceptable in the real world (e.g. earning points through violence) and vice versa (e.g. losing points by following a non-selfish strategy). This is an issue that we are not pursuing further in the context of this research, given that our focus stays centered on the consequences that the presence (or absence) of in-game choices (and thus, of ingame freedom of choice) can have for the quality of player experience, rather than on the consequences that an attempt to transfer such choices in a real-world setting may imply.

In game studies, play is defined as a special kind of a formalized subset of action, within various 'ludic activities' which in turn, are situated within the even more general category of 'being playful' [22]. Fundamental to the discussion of rules and freedom in play is the distinction Roger Caillois [28] introduced by identifying two forms of play, paidia and ludus. According to Caillois, it is possible to approach each kind of game or play form with structures, rules, goals and limits (ludus), or with a more unstructured, spontaneous and free act of play (paidia). Gonzalo Frasca [29] has developed Caillois' theory further and noted how certain games are more clearly designed for a formally defined ludus game play - they are typically focused on winning and losing, the counting of points, and they generally provide players with clearly defined goals in the game play. In contrast, games designed with more open goals, exploration, experimentation and improvisation are more likely to invite a paidia style of free, playful behaviors. MacGregor [30], using Frasca's understanding of Caillois terms, notes that the spectrum between paidia and ludus in relation to digital games operates between ludus as an structured goal-driven type of activity, with clearly defined or formalized rules, and paidia as a freeform type of activity, with undefined goals and undefined but implicit or informal cultural rules. Jesper Juul [31] argued that most digital games can be found on a scale between emergence and progression, and their game guides are consequently a combination of step-by-step descriptions and strategy guides. Finally, Mitgutsch [32] recently noted that while a number of digital games focus on the game-dimension of game play, such as rules, goals and structures - referred to as ludus [28] there are other digital games that focus on the play-dimension of game play, such as unstructured, spontaneous and free act of play referred to by Caillois [28] as paidia.

On this basis it may be concluded that digital games categories can be considered to lie at various points on an axis of play between totally freeform activity and structured goal-driven activity.

The "free-form" end of the axis focuses on the play-dimension of game play, such as unstructured, spontaneous and free acts of play. Games that would lie at this end comprise "free-form" digital games which allow players to choose which challenges they want to overcome or not as well as to choose the order in which they face challenges. Challenges have multiple ways for players to overcome them. Free-form games have no agenda, and the player's goals are entirely intrinsic and personal.

The "formally structured" end of the axis focuses on the game-dimension of game play, such as rules, goals and structures. Games that would lie at this end comprise "formally structured" digital games which have "win" states as well as rules that structure the play, and that guarantee fairness by being applied transparently and equitably to all players. In addition formally structured games offer unique solutions to challenges and confront players with a fixed sequence of challenges, players have to follow a single path to one objective and there are no alternate paths or methods for accomplishing this objective.

In the category of free-form games can be included both mainstream games, (games that are created solely for fun) and serious games, a term for educational games firstly used by Clark Abt back in 1970 [33] (games that are expressly designed with explicit educational purposes). As noted by Bellotti et al. [34, 35] several effective SandBox Serious Games have (a) a spatial organization the virtual world - where knowledge is distributed [36] and that induces spatial information processing and provides landmarks to support orientation [37] and (b) contextualized tasks, that are spread and contextualized in the virtual worlds, that tend to support players in building a suited knowledge structure for the addressed topic(s) [38].

As one more point to frame this discussion, it should be mentioned that too much freedom of choice within a game could indeed make players spend an overly extended amount of time exploring the game world without a particular purpose, thus risking to become lost and frustrated, in case the rest of the game elements (especially the elements contributing to fantasy, in the sense of this term by Malone, such as the game story, the aesthetics of the game world, as well as the 
interaction mechanisms with the game world elements) do not offer an experience which compensates their time investment. On top of that, from a serious game point of view, as noted by researchers like Kirschner et al. [39], unguided discovery is more often than not inefficient due to the structures that constitute the human cognitive architecture. Therefore, from a learning purpose standpoint, it may be better to consider that free-form games could best be integrated in more structured instructional scenarios, in order for tutors to be able to more effectively lead the learning process.

Closing up this discussion, we would like to note that the concept of in-game freedom of choice substantially concerns serious games, in the sense that these games have an inherent learning purpose. If serious games uptake characteristics of free-form play they may be better suited to lead to more engaging and more free-form learning processes (in the sense of an informed balance between over-guidance and under-guidance), and these latter processes may in turn be able to better support innovative approaches to learning and, more generally, to the acquisition of $21 \mathrm{st}$ century transferable skills.

\section{Research methodology}

The expectation and aim of our research were (a) to develop a valid and reliable questionnaire using both the structural characteristics of digital games and students perceptions of the concept of freedom of choice in digital games, (b) to validate items to be used in questionnaire to measure freedom of choice and (c) to identify the factors that underlie freedom of choice in digital games and (d) to provide a formula to predict freedom of choice in digital games. To get deep understanding of the concept of freedom of choice in digital games, we have explored it from both literature as well as from students perceptions.

Our research is divided into two phases: a development phase and a validation phase of the Freedom of Choice (FoC) Questionnaire.

At the development phase two methods were used: literature review and focus groups. A literature review was used to explore the features that a digital game must have to be considering as freeform $[28,29,22,32]$. Four focus groups with 18 fifth grade's students were organised. The composition of the focus groups differed according to game frequency. The first focus groups (FG1) included infrequent gamers (i.e., students who game at least once a month), the second focus groups (FG2) consisted of frequent gamers (i.e., students who game at least once a week) and the third and the forth focus groups (FG3 \& FG4) were a mix of frequent and infrequent gamers. FG1 had four participants of which two were female. FG2 had also four participants of which three were male participants. FG3 had four male participants.

In focus groups discussions students could freely talk and interact with each other about their game experiences. The discussion was clustered around three core questions by means of a semistructured questionnaire. Accordingly, the three core questions were fixed but additional questions could be posed, probing for clarification or more in- depth insights. The three core questions were. (1) Which game do you like the most? (2) Which genres of digital games do you like? (3) Which features of digital games can make you feel free? In this paper, we only discuss the third question about post game experiences. The method of content analysis was utilized through identifying, coding and cataloguing the meaningful content relating to freedom of choice. In the first stage, meaningful and distinct comments were identified in the transcripts. Next an initial list was composed of all comments addressed by the participants of the focus group. Thereafter these comments were grouped into categories. Once the data were organized we finally identified six (6) categories which are presented in the following section.

At validation phase of the $\mathrm{FoC}$ questionnaire internal consistency reliability and factor analyses were performed using principal components analysis to examine the reliability and the validity of the FoC questionnaire. Furthermore, a multiple regression was run in order to predict freedom of choice in digital games from gender, age, familiarity with digital game and frequency of digital game use.

A literature research was conducted to identify the structural characteristics of digital games pertaining to the concept of freedom of choice. The main findings emerging from the literature review are organized in four themes:

(i) Non linear gameplay

Non linear gameplay means that games provide choices for players to make, different paths that the players can take to get from one point to another, from the game's beginning to its end [40,41]. On the contrary, linear gameplay means that players have to follow a single path to one objective and 
there are no alternate paths or methods for accomplishing this objective. Players learn new things in the appropriate order and developers can make sure everything goes as pre-designed.

(ii) Selection of challenges

Free-form games allow players to choose which challenges they want to overcome or not. From games for learning perspective, in particular, such games can result in improving students' learning by increasing their interest due to the pleasant and attractive environment that they offer, often contrary to conventional learning environments. On the contrary, formally structured games have structured activities which confront players with a pre-defined set of challenges, that all need to be overcome [41].

(iii) Multiple solutions to the game challenges

Free-form games allow multiple solutions to the game challenges and enable many different player-generated gameplay paths. Not every player will go about solving a situation in the same way and, given that these alternate solutions are reasonable, almost any challenge must have multiple ways for players to overcome it. Formally structured games offer unique solutions to challenges (every player overcomes a challenge in the same way) and this does not allow players to come up with different ways to proceed in the game [41, 42].

(iv) Free sequence of challenges

In free-form games players have the ability to choose the order in which they face challenges. Giving players choices of different challenges to overcome allows them to put aside a difficult challenge and occupy themselves with another one for a while. After completing the second challenge, players may return to the first gratified and less stressed/better concentrated, and thereby stand a better chance of overcoming it. On the contrary, formally structured games have structured designer-generated activities which confront players with a fixed sequence of challenges. Games with a fixed sequence of challenges allow players access to only one challenge at a time. In order to even attempt a second challenge, players must complete the first one. This is especially frustrating when players cannot overcome a particular challenge and can do nothing else until that challenge is successfully met [41].

\subsection{Findings of focus groups}

After the literature review, four focus group discussions were planned in order to identify how students understand the concept of freedom of choices in adventure digital games.

Most of the students reported that they fill free when they can do what they want into the game world; when there are no rules that players have to follow.

I feel free when I can do what I want in the game, to do things that I can not do in my real life, namely jumping over a player, rolling under cars, finding weapons e.t.c. (boy)

I like games without rules. You can build what you want and you are free to do whatever you want (girl)

Other students reported that they want to follow their own path into the game world. I want to follow my own path, not the one that game has chosen for me (boy) ... I just want to go where it's easier for me (girl)

Some of the students feel free when they can follow their pace into the game.

... play at my own pace and fully enjoy the game (girl)

... I like games that let me make some adjustments in order to follow my own pace (boy)

Other students reported that they feel free into games where there are no win or lose states. They just play for fun rather than to win.

... I like games that there is no way to lose (girl)

... I am amused with games that have no winners or losers (boy)

Some students said that they feel free when they have control over the game character. That gives them flow.

... I love games that let me choose my character's look and shape (girl)

...I'm able to create a unique character that makes the game feel like it is,

in some ways, my own creation (boy)

Finally, some of the students reported that they feel free with digital games when they are able to influence gameplay, namely when they feel part of the game, which leads to players' immersion.

... I want to feel like I am into the game world (girl)

... to put my opinions and personal preferences into the game(girl) 


\section{FoC questionnaire development and refinement}

According to the students' verbal descriptions a digital game is free-form when it has the following characteristics:

(a) Allow players the freedom to do what they want into the game

(b) Allow players to follow different paths into the game

(c) There are no winners or losers

(d) Allow players to follow their own pace into the game

(e) Allow players to have more control over the game character

(f) Allow players' immersion

These findings are important; on the one hand, the first two characteristics (freedom to do what I want into the game - ability to follow different paths into the game) are consistent with findings from previous studies [28, 29, 22, 32]; on the other hand, the last four characteristics constitute new knowledge about the concept of freedom of choice.

Finally, the following nine (9) items, obtained from focus group discussions and review of the literature, were used for the development of the FoC questionnaire items ( 6 from focus groups and 3 from the literature review):

1. I like games that allow me to do what I want into the game

2. I like games that allow me to follow different paths into the game

3. I like games that allow me to follow my own pace into the game

4. I like games that allow me to have more control over the game character

5. I like games that they have no winners or losers

6. I like games that they make you feel part of the game

7. I like games that allow multiple solutions to the game challenges

8. I like games that allow me to choose which challenges I want to overcome or not

9. I like games that allow me to choose the order in which I face challenges

The FoC questionnaire has been completed by student participants of 3rd, 4th, 5th and 6th grades of three primary schools located in Athens, Greece. It was divided into two parts. In the first part, students were asked to rate their agreement with 9 items using a 5-point Likert scale (strongly disagree, disagree, neutral, agree and strongly agree). In the second part of the FoC questionnaire, students were asked to provide demographic information by answering several questions. Specifically, they were asked to specify their age, gender, prior gaming experience and frequency of digital game use.

\section{Validation of the FoC questionnaire}

The findings reported herein are based on a sample of 290 students from three urban public primary schools located in Athens, Greece. Although 311 individuals were recruited for this study, 21 were excluded from the sample due to invalid or incomplete data. In more detail, the 290 participants ( 165 boys and 125 girls) comprise 74 in total 3rd grade students, 764 th grade students, 695 th grade students and 716 th grade students. Students were surveyed on their use of digital games and totally $70.69 \%$ of them play digital games more than 3 years. More than 40 percent of the students (113) use games every day, 30.50\% (85) use games twice a week, 15.60 (44) once a week, 7.45 (21) twice a week and 6.38 (18) once a week.

It is worth noting that before the study a pilot evaluation on 18 students was conducted in order to help us modify the structure and content of the primary questionnaire and to assess the time required to discover mistakes or failures (e.g. problems with questionnaires, processes, etc.). Completion of the interventions was followed by processing and analysis of the collected data in order to find answers to the initial research questions.

\section{Data analysis}

Internal consistency reliability tests was conducted on the responses to survey items; results were discussed, item categories reviewed and named; and exploratory factor analysis (EFA) was performed to validate the items and make final item selections [43, 44]. Statistical analysis was conducted using SPSS software. 
S. Kirginas, D. Gouscos, Development and Validation of a Questionnaire to Measure Perceptions of Freedom of Choice in Digital Games

Using the Kolmogorov-Smirnov test of normality it was determined that research data were not normally distributed and therefore nonparametric tests, such as Mann-Whitney $U$ tests and Kruskal-Wallis Tests, were used to examine the difference between the two related samples.

\subsection{Mean values for individual questionnaire's items}

For each FoC questionnaire's item the average ratings, and correlations of the ratings with age, are presented in Table 1. In our sample, items with the highest score were "I like games that they make you feel part of the game", "I like games that allow me to do what I want into the game" and "I like games that allow me to have more control over the game character". Items with the lowest score were "I like games that they have no winners or losers" and "I like games that allow me to choose the order in which I face challenges"

Table 1. Means and standard deviations for individual questionnaire's items

\begin{tabular}{l|c|c|c}
\hline & Mean & $\begin{array}{c}\text { Std. } \\
\text { Deviation }\end{array}$ & $\begin{array}{c}\text { Analysis } \\
\text { N }\end{array}$ \\
\hline $\begin{array}{l}\text { 1. I like games that allow me to do what I want into } \\
\text { the game }\end{array}$ & 3.86 & 1.373 & 290 \\
\hline $\begin{array}{l}\text { 2. I like games that allow me to follow different paths } \\
\text { into the game }\end{array}$ & 3.48 & 1.349 & 290 \\
\hline $\begin{array}{l}\text { 3. I like games that allow multiple solutions to the } \\
\text { game challenges }\end{array}$ & 3.64 & 1.373 & 290 \\
\hline $\begin{array}{l}\text { 4. I like games that allow me to choose which } \\
\text { challenges I want to overcome or not }\end{array}$ & 3.41 & 1.589 & 290 \\
\hline $\begin{array}{l}\text { 5. I like games that allow me to choose the order in } \\
\text { which I face challenges }\end{array}$ & 2.93 & 1.576 & 290 \\
\hline $\begin{array}{l}\text { 6. I like games that allow me to follow my own pace } \\
\text { into the game }\end{array}$ & 3.68 & 1.453 & 290 \\
\hline $\begin{array}{l}\text { 7. I like games that allow me to have more control } \\
\text { over the game character }\end{array}$ & 3.73 & 1.421 & 290 \\
\hline $\begin{array}{l}\text { 8. I like games that have no winners or losers } \\
\text { 9. I like games that make you feel part of the game }\end{array}$ & 2.71 & 1.645 & 290 \\
\hline
\end{tabular}

\subsection{Internal consistency reliability}

Reliability refers to the ability of a questionnaire to consistently measure an attribute and how well the items fit together, conceptually $[45,46]$. In this research the internal consistency reliability was used to examine the reliability of the questionnaire. Cronbach's was computed to measure the internal consistency of the statements in the questionnaire. Single measure intra-class correlation coefficients (ICCs) were used to explore the test reliability with the test interval. Among children, coefficients in the range of $0.60-0.80$ can be considered as reflecting good test reliability, while values ranging from 0.81 to 1.00 are excellent. The results showed an alpha of 0.804 (Table 2) which indicates a high correlation between the items and the questionnaire is consistently reliable, so they can be summed up to an overall engagement score. If we continue with the release of units, in other words with the standardized value of the variables, then the coefficient Cronbach a will slightly increase the value of $\alpha=0.810$. This means that whether we increase the number of the items, then Cronbach a will take the value of 0.810 .

Table 2. Cronbach's Alpha results

\begin{tabular}{c|c|c}
\hline Cronbach's Alpha & $\begin{array}{c}\text { Cronbach's Alpha Based } \\
\text { on Standardized Items }\end{array}$ & N of Items \\
\hline 0.804 & 0.810 & 9 \\
\hline
\end{tabular}

\subsection{Construct validity of the questionnaire}

The construct validation of the FoC Questionnaire was confirmed by principal component factor analysis. Construct validity refers to the degree to which the items on an instrument relate to the relevant theoretical construct $[46,47]$. Kaiser-Meyer-Olkin (KMO) and Bartlett's test of sphericity 
were conducted prior to exploratory factor analysis (Table 3). The KMO test resulted in a value of 0.836 . This value was above the cut-off level of 0.6 indicating that the sample was adequate to test exploratory factor analysis. The results of Bartlett's test of sphericity were significant $(\mathrm{p}<0.01)$ and the coefficient correlation between items was significant at above the recommended level of 0.30 .

Table 3. KMO and Bartlett's Test

\begin{tabular}{l|l|r}
\hline \multicolumn{2}{l|}{ Kaiser-Meyer-Olkin Measure of Sampling Adequacy. } & 0.836 \\
\hline Bartlett's Test of Sphericity & Approx. Chi-Square & $1,083.89$ \\
& & 3 \\
\cline { 2 - 3 } & df & 36 \\
\cline { 2 - 3 } & Sig. & 0.000 \\
\hline
\end{tabular}

The results of these tests indicated that the data was suitable for conducting exploratory factor analysis.

\subsection{Exploratory factor analysis}

Exploratory factor analysis (EFA) explores and defines factors underlying measurement instruments and ascertains which items should be included and excluded [43, 44, 48]. The exploratory factor was first performed on 9 FoC Questionnaire items in order to reduce variables in to a smaller set, analyze which variables can be grouped and facilitate easier interpretations.

The scree test (Figure 1) produces the following graph, which proceeds to a graphic representation of eigenvalues and guides us to the determination of the number of the essential factorial axes.

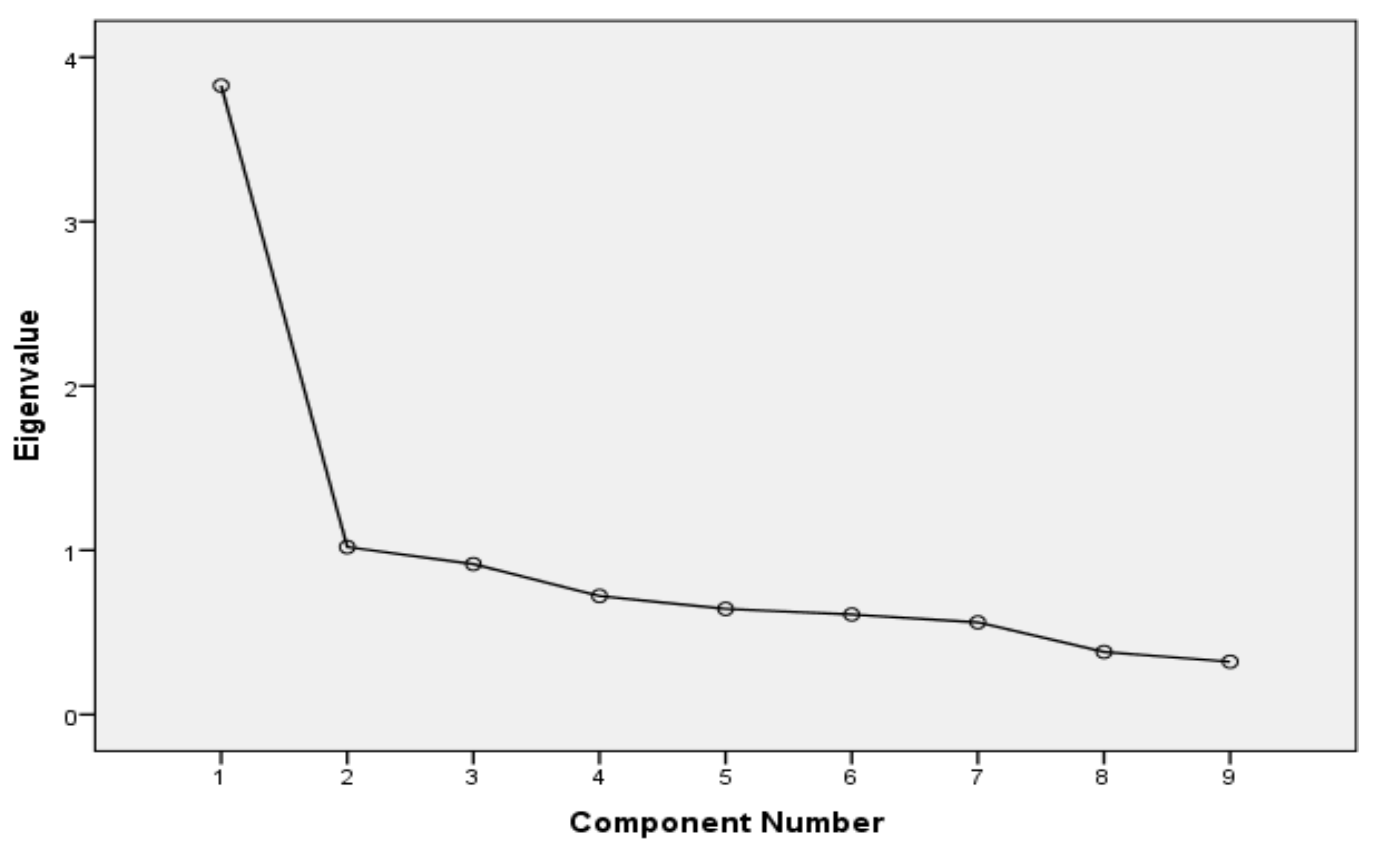

Figure 1. Results of preliminary scree test prior to EFA

The above graph presents a distinguished break up to the second factor, whereas after the second factor an almost linear part of the eigenvalue (Eigenvalues are the variances of the factors) curve follows. Furthermore, principal component analysis resulted in two components extracted (Table 4) with an eigenvalue of $53.860 \%$.

With the two factor model, exploratory factor analysis was performed by means of Varimax, the principal components analysis. Varimax is a type of rotation after the initial extraction of factors, which impose the restriction that the factors cannot be correlated and was chosen because it is generally used for validation studies. Table 4 presents the components and the factor loadings (factor loadings represent how much a factor explains a variable in factor analysis) produced after Principal Components Analysis. 
S. Kirginas, D. Gouscos, Development and Validation of a Questionnaire to Measure Perceptions of Freedom of Choice in

Table 4. Total variance explained

\begin{tabular}{c|c|c|c|c|c|c}
\hline \multirow{2}{*}{ Component } & \multicolumn{4}{|c|}{ Initial Eigenvalues } & \multicolumn{2}{|c}{ Rotation Sums of Squared Loadings } \\
\cline { 2 - 6 } & Total & $\begin{array}{c}\text { \% of } \\
\text { Variance }\end{array}$ & Cumulative & Total & $\begin{array}{c}\text { \% of } \\
\text { Variance }\end{array}$ & $\begin{array}{c}\text { Cumulativ } \\
\mathrm{e}\end{array}$ \\
\hline 1 & 3.828 & 42.532 & 42.532 & 3.784 & 42.045 & 42.045 \\
\hline 2 & 1.020 & 11.328 & 53.860 & 1.063 & 11.814 & 53.860 \\
\hline 3 & .916 & 10.175 & 64.034 & & & \\
\hline 4 & .721 & 8.016 & 72.050 & & & \\
\hline 6 & .643 & 7.147 & 79.196 & & & \\
\hline 7 & .609 & 6.764 & 85.960 & & & \\
\hline 8 & .561 & 6.237 & 92.198 & & & \\
\hline 9 & .381 & 4.232 & 96.430 & & & \\
\hline
\end{tabular}

More specifically, based on student choices as presented by the factor analysis, items 1, 2, 3, 4, 5 , 6,7 and 9 particularly with quite high loadings $(0.689,0.666,0.709,0.655,0.715,0.707,0.681$ and 0.672 ) load mainly on the first factor (Factor 1- F1), represents exploratory freedom in digital games. Item 8 with high loading (0.938) on the second factor (Factor 2 - F2), consist of the represents outcome freedom of digital games (Table 5).

Table 5. Rotated component matrix

\begin{tabular}{l|c|c}
\hline & \multicolumn{2}{c}{ Component } \\
\cline { 2 - 3 } & 1 & 2 \\
\hline 1. I like games that allow me to do what I want into the game & 0.689 & \\
\hline 2. I like games that allow me to follow different paths into the game & 0.666 & \\
\hline 3. I like games that allow multiple solutions to the game challenges & 0.709 & \\
\hline $\begin{array}{l}\text { 4. I like games that allow me to choose which challenges I want to } \\
\text { overcome or not }\end{array}$ & 0.655 & \\
\hline $\begin{array}{l}\text { 5. I like games that allow me to choose the order in which I face } \\
\text { challenges }\end{array}$ & 0.715 & \\
\hline $\begin{array}{l}\text { 6. I like games that allow me to follow my own pace into the game } \\
\text { 7. I like games that allow me to have more control over the game } \\
\text { character }\end{array}$ & 0.707 & \\
\hline 8. I like games that have no winners or losers & 0.681 & \\
\hline 9. I like games that make you feel part of the game & 0.672 & \\
\hline
\end{tabular}

\subsection{Dimensionality analysis}

Significant differences were explored for both two FoC factors for students' gender, age, gaming experience and play frequency.

Gender: The results showed significant differences between players' gender for both factors (Figure 2). Exploratory freedom increased with male gender, $\mathrm{F}=19.445, \mathrm{p}=0.00$ while outcome freedom increased with female gender $(\mathrm{F}=7.128, \mathrm{p}=0.008)$. 
pag. 38

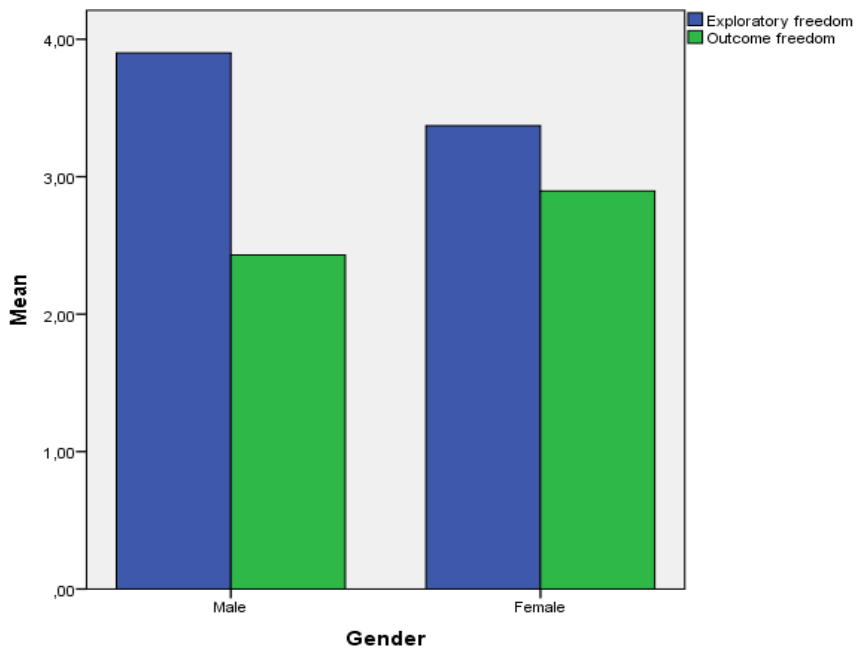

Figure 2: Findings on freedom of choice factors with respect to gender

Age: The results showed significant differences between players' age but only for exploratory freedom (Figure 3). Exploratory freedom decreased with players' age, $F=15.566, p=0.001$. On the contrary, outcome freedom did not show significant differences $(F=3.401, p=0.334)$.

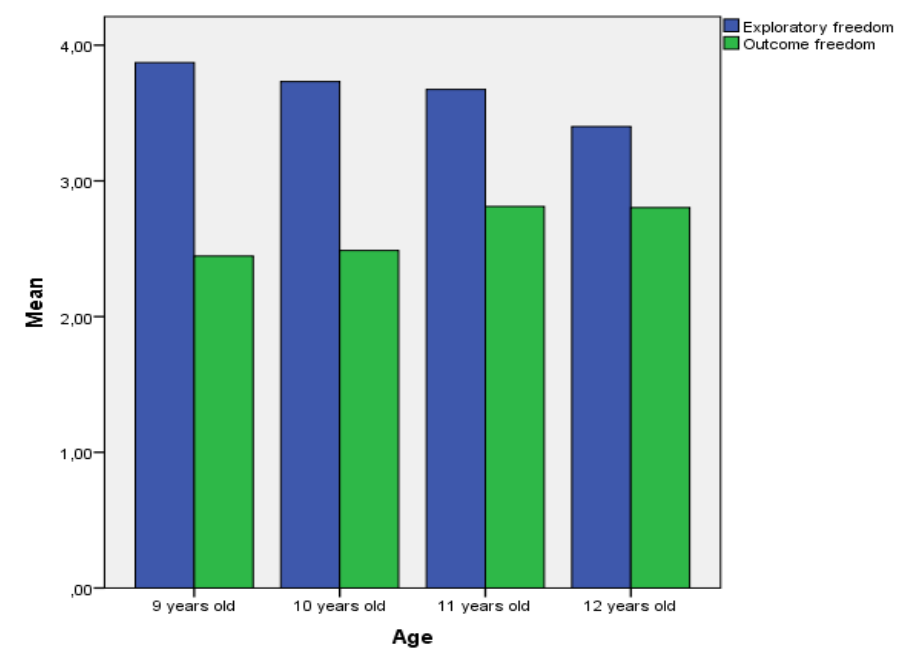

Figure 3: Findings on freedom of choice factors with respect to age

Gaming experience: Students reported how long they play games as an indicator of their experience with games. The results showed significant differences between gaming experience but only for exploratory freedom (Figure 4). Exploratory freedom increased with gaming experience, $\mathrm{F}=13.711, \mathrm{p}=0.008$. On the contrary, outcome freedom did not show significant differences $(\mathrm{F}=2.787, \mathrm{p}=0.594)$. 


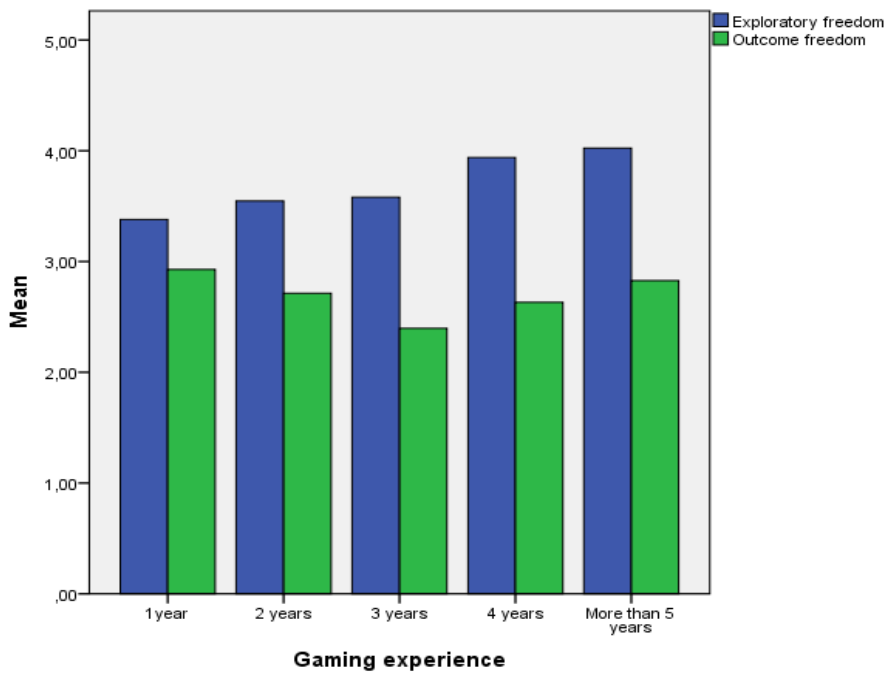

Figure 4: Findings on freedom of choice factors with respect to gaming experience

Frequency of play: Students reported how often they played games as an indicator of their experience with games. The results showed significant differences between play frequencies but only for exploratory freedom (Figure 5). Exploratory freedom increased with play frequency, $\mathrm{F}=23.181, \mathrm{p}=0.00$. On the contrary, outcome freedom did not show significant differences $(\mathrm{F}=6.009, \mathrm{p}=0.198)$.

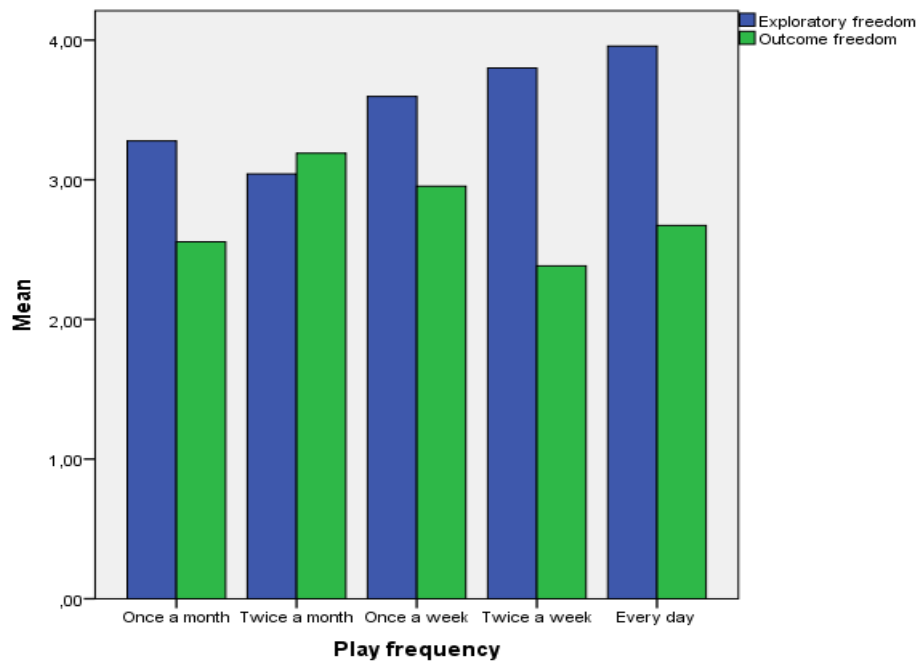

Figure 5: Findings on freedom of choice factors with respect to play frequency

\subsection{Regression model for predicting preferred freedom of choice}

A Mann Whitney U test was used to analyze the concept of freedom of choice across gender. A Mann Whitney U test relies on scores being ranked from lowest to highest; therefore, the group with the lowest rank average is the group with the greatest number of lower scores in it. Similarly, the group with the highest rank average should have greater number of high scores within it. So, the test revealed a statistically significant difference at the level of $p<0.05 \quad(Z=-3.574$; $\mathrm{p}=0.000<0.05$ ). The rank average for male students was 160.80 (mean score 3.74 ), female students had score rank average of 125.30 (mean score 3.32). This result indicates that higher freedom of choice scores was associated with male when compared to female. 
Table 6. Mean and standard deviation across students' gender, age, gaming experience and play frequency

\begin{tabular}{|c|c|c|c|c|}
\hline \multirow{3}{*}{$\begin{array}{l}\dot{\bar{\theta}} \\
\stackrel{0}{0} \\
0\end{array}$} & & Mean & $\mathrm{N}$ & Std. Deviation \\
\hline & Male & 3.74 & 165 & 0.83 \\
\hline & Female & 3.32 & 125 & 0.96 \\
\hline \multirow{4}{*}{$\underset{\&}{\infty}$} & 9 & 3.71 & 74 & 1.00 \\
\hline & 10 & 3.59 & 76 & 0.97 \\
\hline & 11 & 3.58 & 69 & 0.83 \\
\hline & 12 & 3.33 & 71 & 0.80 \\
\hline \multirow{5}{*}{ 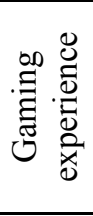 } & 1 year & 3.33 & 30 & 1,07 \\
\hline & 2 years & 3.45 & 51 & 0.86 \\
\hline & 3 years & 3.45 & 75 & 0.89 \\
\hline & 4 years & 3.79 & 69 & 0.63 \\
\hline & More than 5 years & 3.89 & 65 & 0.73 \\
\hline \multirow{5}{*}{ 离 } & Once a month & 3.20 & 20 & 0.99 \\
\hline & Twice a month & 3.06 & 22 & 0.87 \\
\hline & Once a week & 3.53 & 45 & 0.85 \\
\hline & Twice a week & 3.64 & 88 & 0.72 \\
\hline & Every day & 3.81 & 115 & 0.81 \\
\hline
\end{tabular}

A Kruskal-Wallis test was used to analyse the concept of freedom of choice across students' age. The Kruskal-Wallis test showed that there was a statistically significant difference in freedom of choice score between the different age, $Z=12.653, \mathrm{p}=0.04$, with a mean rank of 167.05 (mean score 3.59) for 3rd graders, 151.72 (mean score 3.59) for 4th graders, 143.15 (mean score 3.58) for 5 th graders and 118.66 (mean score 3.33) for 6th graders. This result indicates that higher freedom of choice scores was associated with younger students when compared to older.

As about the freedom of choice across gaming experience, the Kruskal-Wallis test showed that there was a statistically significant difference in freedom of choice score between the different gaming experience, $Z=35.387, p=0.00$. This result indicates that higher freedom of choice scores was associated with higher playing experiences (mean rank 173.81; mean score 3.89).

The Kruskal-Wallis test showed that there was a statistically significant difference in freedom of choice score between the different frequency of digital game use, $Z=19.484, p=0.01$. This result indicates that higher freedom of choice scores was associated with higher frequency of digital game use (mean rank 161.55; mean score 3.81).

A multiple regression was run (Table 7) to predict freedom of choice in digital games from gender, age and familiarity. These variables statistically significantly predicted Freedom, $\mathrm{F}=9.384, \mathrm{p}<$ $0.000, \mathrm{R} 2=0.519$. All variables added statistically significantly to the prediction, $\mathrm{p}<0.05$ except from the variable "Gender" (Sig. 0.118) which doesn't count in significance testing.

Table 7. Regression coefficients

\begin{tabular}{c|c|c|c|c|c|c}
\hline \multicolumn{2}{c|}{ Model } & \multicolumn{2}{c|}{$\begin{array}{c}\text { Unstandardized } \\
\text { Coefficients }\end{array}$} & $\begin{array}{c}\text { Standardized } \\
\text { Coefficients }\end{array}$ & \multirow{2}{*}{ Sig. } \\
\cline { 3 - 7 } \multicolumn{2}{c|}{} & B & Std. Error & Beta & & \\
\hline \multirow{4}{*}{1} & (Constant) & 3.300 & .268 & & 12.334 & .000 \\
\cline { 2 - 7 } & Gender & -.155 & .099 & -.091 & -1.567 & .118 \\
\cline { 2 - 7 } & Age & -.112 & .042 & -.151 & -2.666 & .008 \\
\cline { 2 - 7 } & Gaming experience & .107 & .041 & .164 & 2.633 & .009 \\
\cline { 2 - 7 } & Frequency & .118 & .044 & .168 & 2.664 & .008 \\
\hline
\end{tabular}

The unstandardized coefficients indicate the difference in preferred freedom of choice per unit change in player's gender, age, frequency and familiarity, whereas the standardized indicate the difference in preferred freedom of choice in standard deviations per standard deviation difference in player's gender, age, frequency and familiarity. Many people think the latter is better because someone can directly compare the effects across other predictors but this is not good practice. In a perfect world where all the predictors are measured with the same degree of reliability and there are no outliers or overly influential data points, this might be true but it rarely is the case. In addition, the standardized estimates are more subject to sampling variability. 
Based on these, and using the unstandardized coefficients, the general form of an equation to predict preferred freedom of choice from player gender, age, frequency and familiarity, is:

Predicted preferred freedom of choice $=$

$3.300-(0.155 \mathrm{x}$ gender $)-(0.112 \mathrm{x}$ age $)+(0.107 \mathrm{x}$ familiarity $)+(0.118 \mathrm{x}$ frequency $)$

Thus, for gender (male - female) we need only one dummy variable with a coding scheme of 0 when the individual is male, and 1 when female. For familiarity, we need a dummy variable with a coding scheme of $0=$ no familiarity, $1=$ one year familiarity, $2=$ two years familiarity, $3=$ three years familiarity, $4=$ four years familiarity and $5=$ more than five years familiarity. Finally, for frequency we need a dummy variable with a coding scheme of $1=$ once a month, $2=$ twice a month, $3=$ once a week, $4=$ twice a week and $5=$ every day.

\section{Conclusions}

The 290 valid questionnaires were collected with a view to a pilot study on validity and reliability of the FoC Questionnaire as a research tool. In our sample, items with the highest agreement were "I like games that they make you feel part of the game", "I like games that allow me to do what I want into the game" and "I like games that allow me to have more control over the game character". Items with the lowest score were "I like games that they have no winners or losers" and "I like games that allow me to choose the order in which I face challenges". The adequacy indicator of the sample $\mathrm{KMO}=0.836>0.70$ indicated that the sample data are suitable for the undergoing of factor analysis. The control of sphericity (Bartlett's sign $<0.001$ ) proved that the principal component analysis has a sense. Through this analysis, data grouping was based on the inter-correlation with the aim of imprinting those factors which describe completely and with clarity the participants' attitudes towards the research subject.

According to the analysis, two uncorrelated factors arise, exploratory freedom and outcome freedom, which explain the $53.86 \%$ of the whole inertia of data and are described separately afterwards. The coefficient of internal consistency (reliability) Crobach's a is statistically significant and equals to $80.4 \%$ for the total number of questions. That is why the scale of 9 questions was considered as reliable in terms of internal consistency of the conceptual construction that was composed for the attitudes toward learning statistics with technology. Furthermore, a formula was conducted, using multiple regressions, in order to predict freedom of choice in digital games from different demographic characteristics.

The results of the present study suggest which types of game choices elicit the lowest level of freeform play, and which types of choices reflect the higher level of free-form play. Based on these results we would like to propose that a key factor for the design of effective digital games for learning seems to be the development of games that (a) focus on the play dimension of gameplay, allowing for free, unstructured activities without pre-defined rules and pre-designed goals; (b) create non-linear gameplay; (c) allow multiple solutions to the game challenges and enable many different player-generated gameplay paths; (d) give players the ability to choose the order in which they face game challenges; and (e) allow players to choose which challenges they want to overcome or not, (f) give players the ability have control over the game character, (g) allow players to follow their pace, have no win or lose states, and (i) allow players the ability to influence gameplay. Such games can result in improving students' learning by increasing their interest due to the pleasant and attractive environment that they offer, often contrary to conventional learning environments. When students play with free-form digital games they feel more motivated and engaged with free, non-obligatory and unstructured acts of play, without predefined rules and pre-designed goals. Students in such an environment have the freedom to determine their own learning paths via goals and rules. This, in our view, seems an important factor that makes free-form digital games more challenging than other learning environments. When students play with free-form digital games, the negative emotions caused by failure are weakened, exactly because success can be subjectively defined by the players themselves. Free, unstructured acts of play allow players to discover new skills, try and make mistakes or fail, and then try again without any negative real-world consequences. In such cases, a sense of continued engagement and intrinsic motivation can be sustained during gameplay especially when, according to Malone \& Lepper [12], games include representations of the real world and involve the players' fantasy. Fantasy can offer analogies or metaphors for real world processes that allow players to 
experience the same phenomenon from different perspectives. That means that skills may be learnt more easily when presented in an imaginative context rather than in a conventional learning environment.

On the other hand, we would like to propose that digital games with freedom of play can lead to more engaging and more free-form learning processes, which can better support innovative approaches to learning and, more generally, to the acquisition of 21 st century transferable skills. In the same line of thought, we would also like to propose and further investigate the view that digital games with freedom of play can be used across multiple learning subjects, put students at the centre and engage them actively in the learning process, promoting 21 st century transferable skills such as discovery and experiential learning, collaboration, decision taking, active and critical thinking, creative thinking, problem solving skills. On these premises, school teachers and educators who want to encourage innovative learning processes could use free-form digital games in order to enrich their teaching methods and enhance students' learning.

\section{Research limitations and directions of further research}

It must be mentioned that the research conducted thus far has faced a number of limitations: (a) the focus groups were conducted only with students, without teachers or parents present; (b) the students who participated in both focus groups and validation phase of the FoC Questionnaire expressed their personal perceptions, having no particular experience with the concept of freedom of choice or serious games; and (c) the research focused mainly on primary school students. This has been an explicit design choice, on the premise that this target audience would allow us to more clearly understand eventual differentiations in findings. Still, we acknowledge the need for additional work to determine how the questionnaire performs with other samples, including other school contexts and age groups, as well as with players with previously identified experience with the concept of freedom of choice and/or serious games

However, the work described in this paper is a good starting point for a larger project, including issues such as:

- $\quad$ a survey with a larger sample, including other school contexts and age groups, as well as with players with previously identified experience with the concept of freedom of choice and/or serious games in order to support the generalisability of the FoC Questionnaire and to more fully understand the dimensions of freedom of play to contemporary education demands for accomplishing high achievements,

- a survey of selected games with the research question if there is a significant correlation between the results of FoC Questionnaire and psychophysiological recordings (i.e. skin conductance level, heart rate, facial expressions) in order to draw conclusions about the effectiveness of the questionnaire,

- a development of a set of heuristics for the assessment of freedom of choice in digital games based structural characteristics of digital games and the perceptions of students and/or teachers.

Last but not least, a substantial direction of further research work has to do with the limits that freedom of choice has, as a factor for creating games that offer better experience and higher engagement. Is more and more freedom of choice always better or, in other words, should the objective of serious game design be to maximize freedom of choice at all costs? From our research experience thus far, we feel this may not be the case; too less freedom of choice may indeed deprive players of interesting challenges, whereas at the same time too much freedom of choice may deprive them of interesting constraints which, like challenges, play an integral role in the emergence of engagement. In this respect, the optimal level of freedom of choice for a serious game design may well not be the maximum one, but rather an intermediate level that somehow balances a right mix of freedoms and limits that maximizes engagement and fun. The exploration of this optimum level of freedom of choice seems, at this time, to be one of the most interesting directions of research that we would like to pursue. 


\section{References}

[1] Wiebe, E., Lamb, A., Hardy, M., Sharek, D., Measuring Engagement in Video Game-based Environments: Investigation of the User Engagement Scale, Computers in Human Behavior, (32), 123-132, 2014.

[2] Sweetser, P., Wyeth, P., GameFlow: A model for evaluating player enjoyment in games, Computers in Entertainment, 3(3), 1-24, 2005. http://dx.doi.org/10.1145/1077246.1077253

[3] Csíkszentmihályi, M., Flow: The Psychology of Optimal Experience. New York, NY: Harper \& Row Publishers, Inc, 1990.

[4] Bracken, C.C., Lange, R.L., \& Denny, J., “Online video games and gamers' sensations of spatial, social, and co-presence", In Proceedings of the 2005 FuturePlay Conference. East Lansing, MI, 2005.

[5] Takatalo, J., Hakkinen, J., Komulainen, J., Sarkela, H., Nyman, G., "Involvement and presence in digital gaming", In Proceedings of the 4th Nordic conference on Human-computer interaction: changing roles, Oslo, Norway, ACM Press, 2006. http://dx.doi.org/10.1145/1182475.1182520

[6] McMahan. A., "Immersion, Engagement, and Presence: A Method for Analyzing 3-D Video Games”, In M. J. P. Wolf \& B. Perron (Eds.), The video game theory reader (pp. 67-86). New York: Routledge, 2003.

[7] Brown, E., Cairns, P., "A grounded investigation of immersion in games", In ACM Conference on Human Factors in Computing Systems (pp. 1297-1300), New York, NY: ACM Press, 2004. http://dx.doi.org/10.1145/985921.986048

[8] Ermi, L., Mayra, F., "Fundamental Components of the Gameplay Experience: Analysing Immersion", In Proceedings of Chancing Views - Worlds in Play (vol. 37, pp. 37-53), New York, NY: Peter Lang International Academic Publisher, 2005.

[9] Jennett, C., Cox, A.L., Cairns, P., Dhoparee, S., Epps, A., Tijs T., Walton, A., Measuring and defining the experience of immersion in games, International Journal of Human-Computer Studies, 66, 641-661, 2008. http://dx.doi.org/10.1016/j.ijhcs.2008.04.004

[10] Costello, B., Edmonds, E., "A Tool for Characterizing the Experience of Play", In Proceedings of the Sixth Australasian Conference on Interactive Entertainment (pp. 1-10), Sydney, Australia: ACM Press, 2009. http://dx.doi.org/10.1145/1746050.1746052

[11] Przybylski, A.K., Rigby, C.S., Ryan, R., A Motivational Model of Video Game Engagement. Review of General Psychology, 14(2), 154-166, 2010. http://dx.doi.org/10.1037/a0019440

[12] Malone, T.W., Lepper, M.R., "Making Learning Fun: A Taxonomy of Intrinsic Motivations for Learning”, In R.E. Snow \& M.J. Farr (Eds.), Aptitute, Learning and Instruction: III. Conative and affective process analyses (pp. 223-253) Hilsdale, NJ: Erlbaum, 1987.

[13] Rigby, S., Ryan, R., Glued to Games: How Video Games Draw us In and Hold us Spellbound, Santa Barbara, CA: Praeger, 2011.

[14] Klimmt, C., "Dimensions and determinants of the enjoyment of playing digital games: A three-level model", In Proceedings of the Digital Games Research Conference (pp. 246-257), Utrecht, The Netherlands: Faculty of Arts, Utrecht University, 2003.

[15] IJsselsteijn, W. A., Poels, K., de Kort, Y.A.W., The game experience questionnaire: Development of a self-report measure to assess player experiences of digital games. Eindhoven, The Netherlands: TU Eindhoven. FUGA deliverable D3.3. Technical report, 2008.

[16] Koster, R., A Theory of Fun for Game Design, Scottsdale, AZ: Paraglyph Press, 2004.

[17]Poels, K., de Kort, Y.A.W., IJsselsteijn, W.A., "It is always a lot of fun! Exploring Dimensions of Digital Game Experience using Focus Group Methodology", In Proceedings of Futureplay 2007(pp. 83-89), Toronto, Canada: ACM Press, 2007.

[18] Hassenzahl, M., Tractinsky, N., User Experience - a Research Agenda, Behaviour and Information Technology, 25(2), 2006. http://dx.doi.org/10.1080/01449290500330331

[19] Roto, V., "User Experience from Product Creation Perspective". In E. Law, A. Vermeeren, M. Hassenzahl, M. Blythe (Eds.), Towards a UX Manifesto workshop. Lancaster, UK: COST, 2007.

[20]Egenfeldt-Nielsen, S., Smith, J., Tosca, S., Understanding Video Games: The Essential Introduction, London: Routledge, 2008.

[21] Almeida, S., Veloso, A., Roque, L., Mealha, O., Moura A., "The Video Game and Player in a Gameplay Experience Model Proposal". In Proceedings of Videojogos 2013 - 6th Annual Conference in the Science and Art of Video Games. Coimbra, Portugal: University of Coimbra, Portugal, 2013. 
[22] Salen, K., Zimmerman, E., Rules of play: Game design fundamentals, Cambridge, MA: MIT Press, 2004.

[23] Rollings, A., Adams, E., Andrew Rollings and Ernest Adams on Game Design. Indianapolis, IN: New Riders, 2003.

[24] Wolf, M., Assessing Interactivity in Video Game Design. Mechademia 1: Emerging Worlds of Anime and Manga, of the series Mechademia: An Annual Forum fir Anime, Manga and the Fan Arts, pp. 78-86, 2006. http://dx.doi.org/10.1353/mec.0.0095

[25] Rommeswinkel, H., Measuring freedom in games, University of St.Gallen Law \& Economics Working Paper, 2014.

[26] Björk, S., Holopainen, J., Patterns in Game Design. Charles River Media, 2004.

[27] Rollings, A., Morris, D., Game Architecture and Design. Scottsdale, AZ: Coriolis Group, 2000.

[28] Caillois, R., Man, Play, Games. Chicago, IL: University of Illinois Press, 2001.

[29] Frasca, G., Simulation Versus Narrative: Introduction to Ludology, 2003, [Online]. Available: http://www.ludology.org/articles/VGT_final.pdf.

[30] McGregor, G., "Terra ludus, terra paidia, terra prefab: spatialization of play in videogames \& virtual worlds", In Proceedings of the 5th Australasian Conference on Interactive Entertainment (pp. 31-38), New York, NY: ACM Press, 2008. http://dx.doi.org/10.1145/1514402.1514407

[31] Juul, J., Half-Real: Video Games between Real Rules and Fictional Worlds. Cambridge, MA: MIT Press, 2005.

[32] Mitgutsch, K., Digital Play-Based Learning. A philosophical-pedagogical perspective on learning and playing in computer games, Journal for Information Technology Studies as Human Science 9(3), 2008.

[33] Abt C., Serious Games, New York, Viking Press, 1970.

[34]Bellotti, F., Berta, R., De Gloria, A., Designing effective serious games: opportunities and challenges for research, International Journal of Emerging Technologies in Learning, vol. 5, pp. 22-35, 2010. http://dx.doi.org/10.3991/ijet.v5s3.1500

[35] Bellotti, F., Berta, R., De Gloria, A., Ott, M., Arnab, S., De Freitas, S., Kiili, K., "Designing Serious Games for education: from Pedagogical principles to Game Mechanisms", In Gouscos D. and Meimaris M. (Eds.), Proceedings of 5th European Conference on Game-Based Learning, Oct 2011, Athens, Greece. Academic Publ. Ltd, Reading, UK, pp.26-34, 2011.

[36] Sliney, A., Murphy, D., “JDoc: A serious game for medical learning”, in ACHI '08 Proceedings of the First International Conference on Advances in Computer-Human Interaction, pp. 131-136, IEEE, 2008. http://dx.doi.org/10.1109/ACHI.2008.50

[37] Slater, M., Khanna, P., Mortensen, J., Yu, I., Visual realism enhances realistic response in an immersive virtual environment, Computer Graphics and Applications, IEEE, 29(3), 76-84, 2009. http://dx.doi.org/10.1109/MCG.2009.55

[38] Qin, J., Chui, Y. P., Pang, W. M., Choi, K. S., Heng, P. A., Learning blood management in orthopedic surgery through gameplay, Computer Graphics and Applications, IEEE, 30(2), 45 57, 2010. http://dx.doi.org/10.1109/MCG.2009.83

[39] Kirschner, P.A., Sweller, J., Clark, R.E., Why minimal guidance during instruction does not work: An analysis of the failure of constructivist, discovery, problem-based, experiential, and inquiry based teaching, Educational Psychologist, 41, 75-86, 2006. http://dx.doi.org/10.1207/s15326985ep4102_1

[40] Prensky, M., Digital game-based learning, St. Paul, MN: Paragon House, 2007.

[41] Rouse, R., Game Design Theory and Practice, (2nd Ed.) Plano, TX: Wordware Publishing, Inc, 2015.

[42] Dewar, G., Teaching critical thinking: A Parenting Science guide, 2009. [Online]. Available: http://www.parentingscience.com/teaching-critical-thinking.html

[43] Byrne, M.B., Structural equation modeling with AMOS: Basic concepts, applications, and programming (Multivariate applications series, 2nd ed.), New York, NY: Taylor \& Francis, 2010.

[44]Jung, I., The dimensions of e-Learning quality: From the learner's perspective, Educational Technology Research \& Development, 59, 2010.

[45] Haladyna, T. M., Developing and validating multiple-choice test items, Mahwah, NJ: Lawrence Erlbaum Associates, Inc, 1999.

[46] De Von, H.A., Block, M. E., Moyle-Wright, P., Ernst, D. M., Hayden, S. J., Lazzara, D. J., A psychometric Toolbox for testing Validity and Reliability, Journal of Nursing scholarship, 39 (2), 2007. http://dx.doi.org/10.1111/j.1547-5069.2007.00161.x 
S. Kirginas, D. Gouscos, Development and Validation of a Questionnaire to Measure Perceptions of Freedom of Choice in Digital Games

[47] Kane, M., Current concerns in validity theory, Journal of Educational Measurement, 38, 2001. http://dx.doi.org/10.1111/j.1745-3984.2001.tb01130.x

[48] Green, S. B., Salkind, N. J., Using SPSS for Windows and Macintosh (3rd ed.), Upper Saddle River, NJ: Prentice Hall, 2003. 